\title{
BJRM
}

Bongaya Journal of Research in Management

Volume.3 Nomor 1. Hal 37-45 Tahun 2020. e-ISSN: 2615-8868

Homepage: https://ojs.stiem-bongaya.ac.id/index.php/BJRM

\section{KINERJA KARYAWAN DITINJAU DARI KONDISI DAN MOTIVASI KERJA PADA KARYAWAN PT. PELABUHAN INDONESIA IV (PERSERO)}

\author{
MEASURING CONSUMER PERCEPTION AND PREFERENCE ON \\ ENVIRONMENTALLY FRIENDLY PRODUCTS
}

\author{
Rudi Alfian \\ Aswar \\ Ekonomi Universitas Indonesia Timur ${ }^{1)}$, Psikologi Universitas Indonesia Timur ${ }^{2}$ \\ rudialfian09@yahoo.com ${ }^{1,}$ aswar.phobia@gmail.com²
}

(Diterima: 21 September 2020; direvisi: 23 September 2020; dipublikasikan: 6 November 2020)

2018 -Bongaya Journal for Research inManagement STIEM Bongaya. Ini adalah artikel dengan akses terbuka dibawah licenci CC BY-NC-4.0 (https://creativecommons.org/licenses/by-nc/4.0/).

\begin{abstract}
This study aims to examine and analyze the Effect of Working Conditions and Work Motivation on the Performance of PT. Pelabuhan Indonesia IV (Persero)Makassar Employees. Data collection using primary data with Questionnaire Technique whose population was obtained from all PT. Pelabuhan Indonesia IV (Persero)Makassar employees by using the Slovin formula, amounting to 73 employees. The results of the questionnaire have been tested for validity and reliability, also tested for classic assumptions in the form of assumptions of Normality, Multicollinearity Assumptions, Heteroscedasticity, and Autocorrelation. The method of data analysis uses multiple regression techniques. Based on the results of the analysis, it turns out that the results of the study indicate that the first hypothesis is accepted because it shows the results of the hypothesis test that there is a significant positive effect. Means Working Conditions contributes significantly to employee performance. The second hypothesis is accepted because it shows a significant positive hypothesis test result. Means Motivation contributes significantly to employee performance. The third hypothesis is accepted because Working Conditions and work motivation have a significant positive effect simultaneously on employee performance.
\end{abstract}

Keywords: Working Conditions, Work Motivation, Employee Performance

\begin{abstract}
ABSTRAK
Penelitian ini bertujuan untuk menguji dan menganalisis bagimana Kondisi Kerja dan Motivasi kerja berpengaruh Terhadap Kinerja KaryawanPT. Pelabuhan Indonesia IV (Persero) Makassar. Pengumpulan data menggunakan data primer dengan Teknik Kuesioner yang populasinya diperoleh dari seluruh KaryawanPT. PelabuhanIndonesia IV (Persero) Makasardengan memakai rumus Slovinyang berjumlah 73 karyawan. Hasil kuesioner tersebut telah diuji validitas dan realibiltasnya, juga diuji asumsi klasik berupa asumsi Normalitas, Asumsi Multikolinearitas, Heteroskedastisitas, dan Autokorelasi. Metode analisis data menggunakan teknik regresi berganda. Berdasarkan hasil analisis, ternyata Hasil penelitian menunjukkan bahwa hipotesis pertama diterima karena menunjukkan hasil uji hipotesis terdapat pengaruh positif signifikan. Berarti Kondisi Kerja memberikan kontribusi yang nyata terhadap kinerja karyawan. Hipotesis kedua diterima karena menunjukkan hasil uji hipotesis positif signifikan. Berarti Motivasi kerja memberikan kontribusi nyata terhadap kinerja karyawan. Hipotesis ketiga diterima Kondisi Kerja dan Motivasi Kerja berpengaruh positifs secara signifikan terhadap Kinerja Karyawan.
\end{abstract}

Kata kunci : Kondisi Kerja, Motivasi Kerja, Kinerja Karyawan. 


\section{PENDAHULUAN}

Dalam rangka mewujudkan suatu perusahaan yang kuat dan tangguh tentunya harus didukung oleh sumberdaya yang dimiliki suatu perusahaan baik sumberdaya alam, sumberdaya manusia maupun sumber daya lainnya yang mendukung proses produksi baik jasa ataupun produksi. Tentunya proses produksi ini akan ditentukan oleh beberapa sumberdaya yang ada, salah satunya yaitu sumber daya manusia sebagai bagian yang tidak terpisahkan dari proses produksi. Agar karyawan dapatmencapai tujuan perusahaan, maka perusahaan akan berusaha mewujudkan karyawan yang memiliki kinerja yang sangat baik.

Kinerja karyawansendiri adalah kualitas maupun kuantitas karyawan yang merupakan hasil kerja baik atau perilaku yang aktual sesuai dengan tugas dan tanggung jawabnya (Willyams, 2010). Sedangkan pendapat senada diungkapkan oleh Mangkunegara (Nurcahyani dan Andyani, 2016) merupakan realiasisi dari tugas dan tanggung jawab karyawaan terhadap perusahaan secara maksimal dan sesuai dengan harapan perusahaan.

Pada dasarnya kinerja karyawan merupakan hasil proses yang kompleks, baik berasal dari diri pribadi karyawan (internal factor), keadaan lingkungan perusahaan (external factor) maupun upaya strategis dari perusahaan. Faktor-faktor internal misalnya motivasi, tujuan, harapan, dan lain-lain. Faktor eksternal adalah lingkungan fisik dan non fisikperusahaan. Kinerja yang baik tentusaja merupakan harapan bagi semua perusahaan dan institusi yang mempekerjakan karyawan, sebab kinerja karyawan ini pada akhirnya diharapkan dapat meningkatkan kinerja perusahaan secara keseluruhan.

Jika kinerja karyawan baik maka kinerja perusahaan akan baik pula, demikian sebaliknya, kalau kinerja karyawan tidak baik maka kurang baik pula kinerja perusahaan( Ali et al., 2011). Menurut Wilson (2012), kinerja adalah melakukan suatu kegiatan sesuai dengan tanggung jawabnya dengan hasil seperti yang diharapkan. Dinyatakan bahwa kinerja adalah hasil kerja yang dapat dicapai oleh seseorang atau sekelompok orang dalam suatu organisasi, sesuai dengan wewenang dan tanggung jawab masing-masing, dalam rangka upaya mencapai tujuan organisasi, tidak melanggar hukum dan sesuai dengan moral maupun etika. Yang menjadi indikator peningkatan kinerja karyawan adalah kondisi kerja dan motivasi karyawan. Baik bersumber dari unsuk psikologis maupun unsur fisik.

Kondisi kerja adalah kondisi atau kedaan lingkungan kerja darisuatu organisasi yang menjadi tempat bekerja,kondisi kerja pada penelitian ini dibentuk dari indikator: pengawasan, budaya organisasi, fasilitas, beban kerja, dan lingkungan fisik. Kondisi kerja adalah serangkaian kondisi atau kedaan lingkungan kerja darisuatu organisasi yang menjadi tempat bekerja,kondisi kerja pada penelitian ini dibentuk dari indikator: pengawasan, budaya organisasi, fasilitas, beban kerja, dan lingkungan fisik.

Motivasi Menurut Mathis \& Jackson (Yuswardi,2019) adalah kesesuaian antara harapan dan kenyataan terhadap hasil yang ingin dicapai oleh seseorang dan perkiraan karyawan. Motivasi seseorang ditujukan untuk kebutuhan akan aktualisasi diri, dan merupakan dorongan untuk menjadi seseorang atau sesuai ambisinya dalam mencapai pertumbuhan, pencapaian potensi, dan pemenuhan kebutuhan diri

Menurut Khan et al., (dalam Yuswardi, 2019) disaat lingkungan bisnis organisasi di semua industri sedang mengalami perubahan yang cepat, motivasi memberikan pengaruh pada kinerja karyawan. Karyawan yang termotivasi pada pekerjaannya akan meningkatkan kinerjanya. Oleh karena itu, memotivasi karyawan untuk melakukan yang terbaik adalah kunci peningkatan kinerja karyawan dan motivasi berpengaruh signifikan terhadap kinerja pegawai dan kepuasan kerja (Utami, 2010)

Salah perusahaan yang saat ini meningkatkan kinerja karyawan yaitu PT. Pelabuhan Indonesia IV (Persero) telah mengalami perkembangan yang cukup pesat dan mampu menyesuaikan diri dengan perkembangan lingkungan yang semakin maju. Hal ini dapat dilihat dalam pengelolaan sektor pelabuhan di Indonesia yang cukup signifikan 
sehingga memberikan dampak positif bagi perusahaan atau organisasi.

PT. Pelabuhan Indonesia IV (Persero) yaitu Badan Usaha Milik Negara (BUMN) yang bergerak dibidang jasa yang menyediakan sarana serta prasarana kepelabuhan dalam rangka menunjang kelancaran arus kapal laut, angkutan penumpang, dan pengiriman barang. Berdasarkan hasil pengamatan lapangan yang dilakukan peneliti terkait kondisi kerja pada PT. Pelabuhan Indonesia IV (Persero), peneliti melihat ada beberapa hal yang masih perlu untuk diperbaiki, antara lain: masih kurangnya kapasitas genset untuk menanggulangi pemadaman listrik yang terjadi secara tiba-tiba, ruang kerja yang tidak memiliki alat pengedap suara, sehingga kondisi proyek yang terjadi disekitar pelabuhan dapat terdengar jelas, latar belakang pendidikan juga menjadi salah satu perhatian yang ditemukan peneliti pada PT Pelabuhan Indonesia IV (persero), hal tersebut terlihat dari seorang karyawan dengan latar belakang pendidikannya tidak sesuai dengan jabatan atau pekerjaanya. Kinerja karyawan pada perusahaan tersebut juga perlu lebih ditingkatkan dengan memberikan motivasi dan dorongan kepada para karyawan agar karyawan tersebut dapat bekerja secara efektif dan profesional.Hasil penelitian terdahulu memberikan bukti bahwa kondisi kerja berpengaruh signifikan terhadap kinerja pegawai Nurrohmah (2015). Namun perbedaan hasil penelitian lainnya bahwa kondisi kerja berpengaruh negatif dan tidak signifikan terhadap kinerja pegawai Salutondok dan soegoto (2015).

Tingginya kinerja karyawan pada setiap organisasi dapat dipengaruhi pula oleh motivasi kerja yang dimiliki oleh setiap karyawan. Hasil penelitian terdahulu membuktikan bahwa motivasi kerja berpengaruh positif dan signifikan terhadap kinerja pegawai, Tania (2017). Namun perbedaan hasil penelitian lainnya bahwa motivasi kerja tidak berpengaruh terhadap kinerja pegawai, Hayati (2014).

Berdasarkan hasil temuan dari penelitian terdahulu yang telah dikemukakan, maka dapat digambarkan kerangka konseptual penelitian, seperti pada gambar dibawah ini:

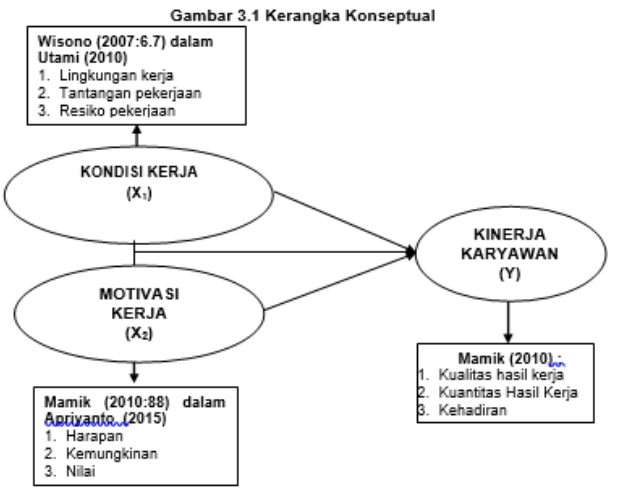

Gambar 1 Kerangka Konseptual

Penelitian ini menguji hipotesis mengenai hubungan dan pengaruh kondisi kerja, motivasi kerja terhadap kinerja karyawan, hipotesis yang akan diuji yaitu :

- Kondisi kerja berpengaruh positif dan signifikan secara parsial terhadap kinerja karyawan PT. Pelabuhan Indonesia IV (persero).

- Motivasi kerja berpengaruh positif dan signifikan secara parsial terhadap Kinerja karyawan PT. Pelabuhan Indonesia IV (persero).

- Kondisi kerja dan motivasi kerja berpengaruh positif dan signifikan secara simultan terhadap kinerja karyawan PT. Pelabuhan Indonesia IV (persero)

\section{METODE PENELITIAN}

Penelitian ini juga menggunakan penelitian konklusif (conclusive research) yang bersifat kausal dimana suatu penelitian yang mempunyai tujuan guna menguji suatu hipotesis yang lebih spesifik atau jelas serta menampilkan hubungan sebab akibat yangmenyatakan adanya pengaruh kondisi kerja(Y)dan motivasi kerja terhadap kinerja karyawan PT. Pelabuhan Indonesia IV (Persero). Lingkungan Kerja (X1) terdiri Tantangan Pekerjaan, Resiko pekerjaan Motivasi kerja(X2) terdiri dari Harapan (expectancy),Kemungkinan(Instrumentality), dan Nilai (value). Kinerja Karyawan(Y) Kualitas hasil kerja, Kuantitas hasil kerja, dan Kehadiran. Populasi sebanyak 271 karyawan, Sampel ditentukan dengan rumus Slovin diperoleh sampel sebanyak 71 orang karyawan. Teknik Pengumpulan Data melalui pembagian kuesioner kepada para anggota (PT Pelabuhan Indonesia IV persero). Analisis data yaitu dilakukan dengan uji validitas dan reabilitas, serta uji prasyarat yaitu normalitas KolmogorovSmirnov (K-S). Jika nilai signifikan uji 
Kolmogorov-Smimov>

Kolmogorov-Smirnov

0.05 ,

(K-S). Jika nilai signifikan uji Linearitas $<0.05$, heterokedistitas. Serta uji Hipotesis denga uju regresi berganda.

\section{HASIL DAN PEMBAHASAN}

Dari Uji Normalitas dipoleh hasil bahwa nilai test statistic yaitu $0.087>0.05$ serta nilai signifikansi yaitu $0.200>0.05$, maka dapat disimpulkan bahwa data dalam penelitian ini terdistribusi normal. Selanjutnya dilakukan uji Hipotesis yaitu uji Parsial (Uji t) dan Uji SimultanF (model).

a. Uji Parsial (Uji t)

Pengujian ini dilakukan untuk mengetahui pengaruh signifikan variabel kondisi kerja dan motivasi kerja terhadap kinerja karyawan secara parsial dan menjawab hipotesis yang telah disusun oleh peneliti dalam penelitian ini. Dasar pengambilan keputusan dalam uji ini yaitu thitung > t-tabel $=1.992$ yang diperoleh dari rumus TINV pada excel dan sig > 0.05, HO ditolak dan Ha diterima maka hipotesis diterima.Hasil pengujian $t$ dapat dilihat dibawah ini :

\section{Tabel 1}

Tabel 1Hasil pengujian parsial $(\mathbf{U j i}-\mathbf{t})$

\begin{tabular}{lll}
\hline Variabel & Nilai & Signifikan \\
\hline Costanta & 0,151 & 0,509 \\
\hline Kondisi Kerja & 0.222 & 0.047 \\
\hline Motivasi Kerja & 0,721 & 0.000
\end{tabular}

Sumber Data: Primer Penelitian

Pada pengujian variabel kondisi kerja menujukkan t-hitung (2.024) > t-tabel (1.992) dan nilai signifikan sebesar $0.047>0.05$ maka $\mathrm{H}_{\mathrm{a}}$ diterima dan $\mathrm{H}_{\mathrm{O}}$ ditolak. Dapat dikatakan bahwa kondisi kerja secara parsial berpengaruh positif dan signifikan terhadap kinerja karyawan pada PT. Pelabuhan Indonesia IV (Persero) Makassar, sehingga hipotesis pertama dalam penelitian ini diterima.

Pada pengujian tabel 1 variabel motivasi kerja menujukkan t-hitung (2.024) < t-tabel (1.992) dan nilai signifikan sebesar $0.000<0.05$ maka $\mathrm{H}_{\mathrm{a}}$ diterima dan $\mathrm{H}_{\mathrm{O}}$ ditolak. Dapat dikatakan bahwa motivasi kerjasecara parsial berpengaruh positif dan signifikan terhadap kinerja karyawan pada PT. Pelabuhan Indonesia IV (Persero) Makassar, sehingga hipotesis kedua dalam penelitian ini diterima.

\section{b. Uji F (model)}

Uji model dalam penelitian ini digunakan untuk menguji apakah model yang disusun peneliti dapat diterima dan dilanjutkan ke analisis data selanjutnya. Data pengambilan keputusan dalam uji model ini yaitu F-hitung > F-tabel $=3.127$ yang diperoleh dari rumus FINV pada excel, maka model tersebut diterima. Hasil uji model dapat dilihat di bawah ini :

Tabel 2. Uji Model F

\begin{tabular}{lll}
\hline Variabel & F & Signifikan \\
\hline $\begin{array}{l}\text { Kondisi Kerja, } \\
\text { Motivasi Kerja } \\
\text { Terhadap }\end{array}$ & 221.123 & 0.000 \\
Kinerja & & \\
\hline
\end{tabular}

Sumber Data: Primer Penelitian

Hasil pengujian model diperoleh nilai Fhitung (221.123) > F-tabel (3.127), sehingga hasil tersebut menujukkan bahwa data yang digunakan dalam penelitian ini dipandang sesuai (memenuhi kriteria model) bahwa nilai F-hitung > F-tabel yang berarti kondisi kerja dan motivasi kerja berpengaruh signifikan secara simultan terhadap kinerja karyawan.

\section{Uji Determinasi ( R2 )}

Uji determinasi dalam penelitian ini bertujuan untuk guna mengukur seberapa jauh kemampuan model bisa menjelaskan total pengaruh variablevariabel independen. Dalam pengujian hipotesis ini koefisien determinasi dapat dilihat dari sebereapa besarnya nilai R-Square (R2), Untuk mengetahui seberapa jauh variable independen likuiditas terhadap kinerja keuangan dimoderasi profitabilitas. Nilai R2 mempunyai interval 0 sampai $1(0 \leq \mathrm{R} 2 \leq 1)$. Jika $\mathrm{R} 2$ bernilai besar (mendekati 1) berarti variable independen dapat memberikan hampir semua informasi yang dibutuhkan untuk memprediksi variable dependen. Sedangkan jika R2 bernilai kecil berarti kemampuan variable bebas dalam menjelaskan variable dependen sangat terbatas.

\section{a. Pengaruh Kondisi Kerja Terhadap Kinerja Karyawan}

Pengaruh kondisi kerja terhadap kinerja pegawai dapat dibuktikan dengan nilai koefisien yang terstandarisasi (Unstandardized Coefficients) yaitu bernilai (0.258) mengartikan bahwa kondisi kerja berpengaruh positif terhadap kinerja karyawan. Maka dari penjelasan tersebut, kondisi kerja pada perusahaan, dapat 
meningkatkan kinerja karyawan begitupun sebaliknya jika kondisi kerja tidak diperhatikan.

Hasil tersebut didukung dengan nilai t-hitung (2.024) > t-tabel (1.992) dan nilai signifikan sebesar $0.47>0.05$ maka $\mathrm{H}_{\mathrm{a}}$ diterima dan $\mathrm{H}_{\mathrm{O}}$ ditolak. Dapat dikatakan bahwa kondisi kerja secara parsial berpengaruh positif dan signifikan terhadap kinerja karyawan pada PT. Pelabuhan Indonesia IV (Perseo) Makassar, sehingga hipotesis pertama dalam penelitian ini diterima.

Fakta lainya, kondisi tersebut diakibatkan karena pegawai yang mampu menyelesaikan tugasnya sesuai target. Hal ini dibuktikan dari tanggapan responden dari indikator terpenting dalam variabel Kondisi kerja $\left(\mathrm{X}_{1}\right)$ tantangan pekerjaan $\left(\mathrm{X}_{1.2}\right)$ disebabkan indikator tersebut memiliki nilai rerata tertinggih dibandingkan indikator lainnya dalam veriabel kondisi kerja $\left(\mathrm{X}_{1}\right)$.

Hasil penelitian ini sejalan dengan pendapat menurut Salutondok dan Soegoto (2015) kondisi kerja disini adalah segala sesuatu yang ada c. dilingkungan kerja karyawan yang dapat mempengaruhi dirinya dalam menjalankan tugas, seperti temperatur, kelembaban, ventilasi, penerangan, kegaduhan, kebersihan tempat kerja, kondisi alat-alat kerja, dan ketidak jelasan tugas serta tanggung jawab.

\section{b. Pengaruh Motivasi kerja Terhadap Kinerja Karyawan}

Pengaruh motivasi kerja terhadap kinerja pegawai dapat dibuktikan dengan nilai koefisien yang terstandarisasi (Unstandardized Coefficients) yaitu bernilai (0.713) mengartikan bahwa motivasi kerja berpengaruh positif terhadap kinerja karyawan. Maka dari penjelasan tersebut, motivasi kerja yang dilakukan pada perusahaan, dapat meningkatkan kinerja karyawan begitupun sebaliknya jika motivasi kerja tidak dilakukan.

Hasil tersebut didukung dengan nilai t-hitung (6.565) < t-tabel (1.992) dan nilai signifikan sebesar $0.000<0.05$ maka $\mathrm{H}_{\mathrm{a}}$ diterima dan $\mathrm{H}_{\mathrm{O}}$ ditolak.Dapat dikatakan bahwa motivasi kerja secara parsial berpengaruh positif dan signifikan terhadap kinerja karyawan pada PT Pelabuhan Indonesia IV (Persero) Makassar, sehingga hipotesis kedua dalam penelitian ini diterima.

Fakta lainya, kondisi tersebut diakibatkan karena karyawan memiliki akses kepada pimpinan tentang berbagai peluang untuk dipromosikan sehingga karyawan dapat termotivasi dalam bekerja.Hal ini dibuktikan dari tanggapan responden dari indikator terpenting dalam variabel motivasi kerja adalah kemungkinan $\left(\mathrm{X}_{2.2}\right)$ disebabkan indikator tersebut memiliki nilai rerata tertinggi dibandingkan indikator lainnya dalam variabel motivasi kerja $\left(\mathrm{X}_{2}\right)$.

Hasil penelitian ini sejalan dengan pendapat menurut Menurut Arini dkk, (2015) Motivasi kerja merupakan suatu keadaan atau kondisi yang mendorong karyawan mengeluarkan tingkat upaya yang tinggi untuk mencapai tujuan perusahaan. Motivasi kerja yang diperoleh karyawan menjadi faktor penentu dalam keberhasilan suatu perusahaan.

Berbeda dengan hasil penelitian yang dilakukan Hayati (2014) menyatakan bahwa motivasi kerja mempunyai pengaruh yang negatif dan tidak signifikan terhadap kinerja karyawan.

\section{Kondisi kerja dan motivasi kerja berpengaruh positif dan signifikan secara simultan terhadap kinerja karyawan}

Pengujian variabel simultan dilakukan dengan membandingkan nilai diperoleh dari nilai pearson correlation dengan nilai Standardized Coefficients. Diperoleh kedua variabel berpengaruh positif dan signifikan secara simultan terhadap kinerja karyawan yaitu sebesar 85.18\%.maka dapat disimpulkan hipotesis ketiga diterima.

Hasil ini didukung dari pengamatan lapangan yang dilakukan terkait kondisi kinerja pada PT. Pelabuhan Indonesia IV (Persero), peneliti melihat ada beberapa hal yang masih perlu untuk diperbaiki, antara lain: masih kurangnya kapasitas genset untuk menanggulangi pemadaman listrik yang terjadi secara tiba-tiba,ruang kerja yang tidak memiliki alat pengedap suara, sehingga kondisi proyek yang terjadi disekitar pelabuhan dapat terdengar jelas, latar belakang pendidikan juga menjadi salah satu perhatian yang ditemukan peneliti pada PT Pelabuhan Indonesia IV (persero), hal tersebut terlihat dari seorang karyawan dengan latar belakang pendidikannya tidak sesuai dengan jabatan atau pekerjaanya. Kinerja karyawan pada perusahaan tersebut juga perlu lebih ditingkatkan dengan memberikan motivasi dan dorongan kepada para karyawan agar karyawan tersebut dapat bekerja secara efektif 
dan profesional. Dalam hal ini peneliti melihat beberapa karyawan yang kurang disiplin dalam menyelesaikan tugas-tugas yang diberikan, sehingga berakibat pada menumpuknya pekerjaan karena tidak terselesaikannya sesuai dengan waktu yang telah ditentukan.

\section{KESIMPULAN DAN SARAN}

Hasil penelitian tentang kondisi kerja Terhadap kinerja karyawan diterima, hal ini diperoleh dari hasil analisis regresi yaitu bahwa kondisi kerja secara parsial berpengaruh dan signifikan terhadap Kinerja Karyawan atau dengan kata lain hasil dari Hipotesis diterima. Pengujian kedua Motivasi Kerja berpengaruh Terhadap Kinerja Karyawan, hal ini diperoleh dari hasil analisis regresi sehingga hipotesis kedua di terima.Berdasarkan pengujian korelasi, ternyata hasil penelitian membuktikan bahwa variable Kondisi Kerja (X1) dan variable Kondisi Kerja (X2) berpengaruh signifikan secara simultan terhadap Kinerja Karyawan (Y) dengan hipotesis ketiga diterima.

\section{DAFTAR PUSTAKA}

Analisa, Lucky. (2011). Analisis Pengaruh Motivasi Kerja dan Lingkungan Kerja Terhadap Kinerja Karyawan.Skripsi. Semarang: Universitas Diponegoro

Apriyanto, Wawan. (2015). Pengaruh Gaya Kepemimpinan Transformasional dan Motivasi Kerja Terhadap Kinerja Karyawan.Jurnal llmu Dan Riset Manajemen 4(11)

Arifianto dkk, (2017). Pengaruh Karakteristik Penyuluhan, Kondisi Kerja, Motivasi Terhadap Kinerja Penyuluhan Pertanian dan Pada Perilaku Petani Padi di Kabupaten Rembang.Jurnal Sosial Ekonomi Pertanian.1 (2):166-180

Arini dkk, (2015). Pengaruh Kemampuan Kerja dan Motivasi Kerja Terhadap Kinerja Karyawan (Studi Pada Karyawan PT Perkebunan Nusantara X Pabrik Gula Djombang Baru). Jurnal Manajemen, 2 (1): 1-9

Bangun, Wilson. (2012). Manajemen Sumber Daya Manusia. Jakarta: Erlangga.

Budiningsih, Setyo, dkk, (2017). Hubungan Pengembangan Karir dan Kompensasi Terhadap Kepuasan Kerja dan Implikasinya Pada Komitmen Organisasional PT. Pertani (persero), Wilayah Jateng \& DIY. Jurnal Manajemen, 3(3)

Fahmi, I. (2016). Pengantar Manajemen Sumber Dasya Manusia Konsep dan Kinerja (Edisi Pert). Jakarta: Mitra Wacana Media.

Febriani, Retno. (2018). Pengaruh Stres Kerja, Etos Kerja dan Motivasi Terhadap Kinerja Pegawai Pada Dinas PERDAGKUM kab. Ponorogo. Skripsi. Universitas Muhammadiyah Ponorogo.

Ghozali, Imam (2011). Aplikasi Analisis Multivariate Dengan Program IBM SPSS 19 Edisi 5. Semarang: Badan Penerbit Universitas Diponegoro.

Hartanto dkk, (2016). Buku Ajaran Manajemen Sumber Daya Manusia II. Ponorogo: UNMUH PONOROGO PRESS.

Hayati, (2014). Pengaruh Motivasi, Lingkungan Kerja, Fasilitas Terhadap Kinerja Karyawan Pada PT. Radio Suara Singgalang Mahimbau (Radio Sushi FM) Padang. Jurnal Manajemen:1-15

Mahesa, Deewar. (2010) Analisis Pengaruh Motivasi dan Kepuasan Kerja Terhadap Kinerja Karyawan Dengan Lama Kerja Sebagai Variable Moderating. Skripsi Semarang: Universitas Diponegoro

Mamik, (2010). Pengaruh Gaya Kepemimpinan, Motivasi Kerja, dan Komitmen Organisasi Terhadap Kinerja Karyawan, Jurnal Ekonomi, 20 (1)

Data, M. U., \& Tafsir, M. (2019). Pengaruh Kepemimpinan, Mmotivasi dan Budaya Organisasi terhadap kinerja pegawai. SEIKO : Journal of Management \& Business, 2(2),113-130.

Ni Made Nurcahyani dan IGA Dewi Adnyani “"Pengaruh Kompensasi Dan Motivasi Terhadap Kinerja Karyawan Dengan Kepuasan Kerja Sebagai Variabel Intervening" E-Jurnal Manajemen Unud, Vol. 5, No.1, 2016: 500 - 532 ISSN: 23028912

Nurrohmah, Khanifah. (2015). Pengaruh Kondisi Kerja, Gaya Kepemimpinan dan Stres Kerja Terhadap Kinerja Karyawan CV..Nova Furniture di Boyolali. Skripsi. Surakarta: Universitas Muhammadiyah Surakarta.

Salutondok, Soegoto. (2015). Pengaruh Kepemimpinan, Motivasi, Kondisi Kerja dan Disiplin Terhadap Kinerja Pegawai di Kantor Secretariat DPRD Kota Sorong. Jurnal EMBA,3 (3): Hal.849-862

Sudaryono, (2018). Metodologi Penelitian. Cetakan ke-2. Depok: Rajawali Pers. 
Sugiyono, M. (2009). Metode Riset Untuk Bisnis dan Ekonomi: Bagaimana Meneliti dan Menulis Tesis, Penerbit Erlangga, Jakarta.

Sugiyono, (2012). Metode Penelitian Kuantitatif dan $R \& D$. Bandung: Alfabeta

Suliyanto. (2011). Ekonometrika Terapan: Teori dan Aplikasi Dengan SPSS Yogyakarta: andi

Sriwati, (2017). Pengaruh Kompensasi Kompensasi, Kepemimpinan, Stimulasi Sosial dan Kerja Serta Kondisi Kerja Terhadap Kepuasan Kerja Karyawan Di Rumah Sakit Baptis Batu. Jurnal Dimensi $5(2)$

Tania, (2017). Pengaruh Gaya Kepemimpinan Transformasional dan Motivasi Kerja Terhadap Karyawan Pada PT. Premier Management Consulting, AGORA,5 (1)

Taurisa dan Ratnawati, (2012). Analisis Pengaruh Budaya Organisasi dan Kepuasan Kerja Terhadap Komitmen Organisasional Dalam Meningkatkan Kinerja Karyawan (Studi Pada PT. Sindo Muncul Kaligawe Semarang). Jurnal Bisnis dan Ekonomi (JBE), 19 (1). 170-187.

Utami, Ari. (2010). Pengaruh Kepemimpinan, Kondisi Kerja, dan Rekan Kerja Terhadap Semangat Kerja Pegawai Dinas Pendidikan Kabupaten Semarang. Skripsi. Semarang: Universitas Negeri Semarang

Willyams. (2010). Pengaruh Kondisi Kerja, Hubungan Kerja dan Kepuasan Kompensasi Terhadap Kinerja Karyawan. Skripsi. Yogyakarta: Universitas Sanata Dharma

Widyacahya, Wulandari. (2018). Pengaruh Pengawasan Kondisi Kerja Terhadap Keterlibatan Kerja Karyawan Rumah Sakit Mata Undaan Surabaya. Jurnal Administrasi Kesehatan Indonesia 6(1)

Yahyo dkk,. (2013). Pengaruh Motivasi, Lingkungan Kerja, Kompensasi Terhadap Kinerja Karyawan Melalui Semangat Kerja Karyawan (Studi Pada Karyawan Bagian produksi CV. Putra Jaya Sahitaguna, Semarang). Diponegoro Jurnal Of Social and Politic: $1-12$

Yuswardi, 2019 Faktor-Faktor yang mempengaruhi Kinerja pada Karyawan Bank di Batam. Jurnal Ekonomi \& Ekonomi Syariah Vol 2 No.1,Januari 2019E-ISSN: 2599-3410 P-ISSN: 4321-1234 